\title{
The Design Process in the Improvement of The Experience Between a Brand and its Target Audience Through a Digital Product: The Lexus Portugal's used Car Website Case Study
}

\author{
Nuno Martins, ${ }^{1, *}$, Juan-Ramon Martin-Sanroman ${ }^{2}$, Fernando Suárez-Carballo² \\ ${ }^{1}$ Polytechnic Institute of Cavado and Ave /ID+, Barcelos, 4750-810, Portugal \\ ${ }^{2}$ Facultad de Comunicación de la Universidad Pontificia de Salamanca, Salamanca, 37007, Spain
}

\begin{tabular}{l} 
A R T I C L E I N F O \\
\hline Article history: \\
Received: 24 July, 2020 \\
Accepted: 21 September, 2020 \\
Online: 05 October, 2020 \\
\hline
\end{tabular}

Keywords:

Design Process

Lexus Portugal

UI \& UX Design

Digital Design

Communication Design

\begin{abstract}
A B S T R A C T
The study aims to demonstrate how the use of the design process can align a brand's strategy with the interests of its target audience through a digital product based on a case study. Currently, Lexus internal studies show that there is a possibility to meet the needs of new audiences, beyond the traditional ones (men, 50+). In order to achieve this goal, the following objectives have been defined: communicate the brand and its cars' main values and philosophy, namely ecology, economy, safety and comfort; promote its services and products; and design an interface that guarantees users easy, pleasant and attractive navigation. The work process consisted of identifying the brand's strategy and values, identifying users, analyzing the main competing brands in the market, and designing a prototype within the framework of User-Centered Design, for which it had to address crucial issues such as the application of character models, UX and UI design, the creation of wireframes and user flows, interface design and the development of usability tests. The results demonstrate that it is possible to align the strategic interests of brands with the needs, objectives and expectations of users in a context of increasing global concerns of citizens related to reuse and sustainability. In this sense, it is vitally important that brands adopt Design processes in order to converge their own brand interests with people's demands.
\end{abstract}

\section{Introduction}

The research arose from a proposal by the Salvador Caetano Group (official representative of the Lexus brand in Portugal) for developing an official website meant specifically for promoting pre-owned Lexus cars in the Portuguese market.

According to Lexus Portugal, its clientele is mainly males, aged 50 and above. However, studies done by the brand regarding the used cars sector in the Portuguese market show that Lexus products and services have a high potential for growth in new market segments such as women and youth, aging 30 and above. This potential is associated with certain intrinsic factors of the brand, namely:

- Hybrid Technology: in the first half of 2020, 99\% of Lexus used cars available for sale had hybrid engine technology. Cars with this technology are all equipped with an automatic gearbox, which facilitates the driving experience and ensures

*Corresponding Author: Nuno Martins, nunomartins.com@gmail.com better safety. This technology also results in low pollutant emissions, thereby having a reduced impact on human health. These attributes are valued by the identified market segments (women and youth) that are typically more conscious about environmental concerns.

- The "Lexus Safety System" available on a significant sample of used cars: this system avoids a considerable volume of accidents through alerts and direct intervention in the driving process. Safety is an attribute particularly valued by women and families that have children.

- The reliability of the cars: there is a proven low probability of breakdown, especially of the type that renders the car nonfunctional and non-operable. The reliability factor in the used car sector specifically appeals to younger clients who have a greater probability of acquiring pre-owned cars at more accessible price points.

Additionally, certain extrinsic factors also affect purchase decisions, such as: 
- Lexus' main competitors in the premium segment (BMW, Mercedes-Benz, Audi, and Volvo) do not have a specific focus on the female audience in their used-vehicle programs. Therefore, there lies an opportunity for gaining advantage through leveraging a differentiating element.

- Citizens tend to be more aware of the more environment friendly motorizations (hybrid and electric). The supply of competing engines in their used-vehicle programmes is predominantly diesel, and there is little to no supply of more eco-friendly engines.

For this set of factors, Lexus Portugal has considered it timely and pertinent to develop a communication strategy that caters specifically to women and youth.

The current official Lexus Portugal website, in this regard, is presently the only source for accessing pricing and availability rated information of pre-owned Lexus vehicles. However, it does not provide the user with a pleasant and properly informed brand experience. According to Lexus Portugal, this has been a restrictive factor in its approach to the new market segments, and has, therefore, affected used car sales targets.

The research has accordingly required multidisciplinary skills and expertise to develop a communication strategy that answers to the concerns and expectations as outlined by to Lexus Portugal. The study took into account not only internal studies made available by Lexus Portugal, but also references related to car sales and drivers' consumption habits [1-3].

\section{General and specific objectives}

The main objective is to verify if the design process can make the users' needs converge with the brands' strategic lines by developing a digital platform through a case study.

To achieve the general objective, a further number of specific tasks were listed:

- To make an integrated list of the objectives proposed by Lexus for the new online platform, and systematize the entire work process to be developed - Together with the teams of Lexus Portugal and Portugal-based advertising agency Caetsu (responsible for advertising and communication at Lexus Portugal), a workplan was created to analyse all information and define the research aims and the stages of the development process.

- To develop a comparative analysis of the main online reference platforms in order to make a note of good solutions and potential problems. The objective of this analysis was to contribute to a better understanding of the identified market and to arrive at a starting set of guidelines towards designing the new solution.

- To use a design methodology that, close to the User-Centred Design framework, allows to design an online platform capable of aligning the interests defined from the brand strategy and the user experience in general terms.

\section{Methodologies}

The methodology adopted aimed to apply key practices associated with process design, namely UX and UI Design, the application of persona models, the creation of wireframes and user flows, the design of interfaces, and the development of usability tests [4-6]. The process consisted of analysis, discussion and resolution making in a collaborative manner among the various stakeholders regarding the different problems associated with the design and development of the online platform [7, 8]. The research process involved, besides the researchers (from the Digital Design area), teams from Lexus Portugal (namely, the General Management, the Marketing team and the Sales team), and the advertising agency Caetsu, alongside a select number of test users $[9,10]$.

Towards initiating the design process, the research team met with executives from Lexus Portugal and Caetsu with the purpose of: comprehending the philosophy of the Lexus brand; discussing the objectives of the new online platform to be developed; discerning the market and the target audience; and defining the strategies and the work process [11-13].

In order to better understand the respective market, a comparative analysis was developed taking into consideration the online platforms belonging to Lexus's main competitors such as Mercedes-Benz, BMW, Audi, and Volvo, alongside websites of multi-brand vendors such as StandVirtual and CarNext. This made it possible to map the brand's territory, and gain an understanding of the communication that has been developed with audiences online.

Later on, a further set of meetings were held with Lexus Portugal and Caetsu for presenting the analysis results and defining the structure of the information architecture pertaining to the online platform [14].

Correspondingly, the third phase of the project, saw the design of the online platform being supported through the building of an extensive collection of visual elements, in order to expedite the development of the project. Subsequently, visual prototypes were developed, wherein, the interface design incorporated concepts and graphic language previously defined by Lexus [15].

The last phase of the research was dedicated to the development of a high-fidelity prototype, and to carrying out usability tests in order to observe user behavior, detect problems, and make the required improvements towards guaranteeing the best possible experience [16].

\section{Comparative analysis of the online platforms of the main competing brands}

In order to arrive at an effective overview of the main competing brands' strategic approach, an analysis of the respective online platforms was first conducted. The platforms of MercedesBenz, BMW, Audi, and Volvo were hence analysed, alongside with two premier multi-brand used car platforms in Portugal, StandVirtual and CarNext.

The goal was to study the strengths and weaknesses of each of the online platforms, with the objective of obtaining relevant knowledge to be later applied in the development of the new Lexus online platform $[17,18]$.

The development process began with an analysis of the navigation structure and the identification of the various functionalities of each of the online platforms. As can be seen in 
Table 1, BMW's online platform was found to be the most complete in terms of functionalities and it also had the most extensive communication strategy. The brand's website was not limited to only providing search tools for its wide range of cars, but also provided the possibility of accessing further detailed information about its services - which was illustrated and animated with photos and videos, that were emotionally engaging, and emphasized the brand's core values and philosophy.

Table 1: Identification of the functionalities of the online platforms of competing brands (January, 2020). Source: own elaboration

\begin{tabular}{|c|c|c|c|c|c|c|}
\hline Features & $\begin{array}{c}\text { Mercedes } \\
\text {-Benz }\end{array}$ & BMW & Audi & Volvo & $\begin{array}{c}\text { Stand } \\
\text { Virtual }\end{array}$ & $\begin{array}{l}\text { Car } \\
\text { Next }\end{array}$ \\
\hline Login/Logout & $\mathrm{X}$ & & & & $\mathrm{X}$ & \\
\hline Favorites & & $\mathrm{X}$ & & $\mathrm{X}$ & X & \\
\hline Comparator & & $\mathrm{X}$ & & $\mathrm{X}$ & & \\
\hline Configurator & $X$ & $\mathrm{X}$ & $\mathrm{X}$ & $\mathrm{X}$ & $\mathrm{X}$ & $\mathrm{X}$ \\
\hline News & & $\mathrm{X}$ & & & $\mathrm{X}$ & $\mathrm{X}$ \\
\hline $\begin{array}{l}\text { Product } \\
\text { Highlights }\end{array}$ & & $\mathrm{X}$ & $\mathrm{X}$ & $\mathrm{X}$ & $\mathrm{X}$ & $\mathrm{X}$ \\
\hline Testimonies & & & & & & $\mathrm{X}$ \\
\hline $\begin{array}{l}\text { Image } \\
\text { Galleries }\end{array}$ & X & X & X & $\mathrm{X}$ & $\mathrm{X}$ & $X$ \\
\hline $\begin{array}{l}\text { Videos/ } \\
\text { Animations }\end{array}$ & & $\mathrm{X}$ & & & & \\
\hline Languages & & & & & & $\mathrm{X}$ \\
\hline Prices & $\mathrm{X}$ & $\mathrm{X}$ & $\mathrm{X}$ & $\mathrm{X}$ & $\mathrm{X}$ & $\mathrm{X}$ \\
\hline $\begin{array}{l}\text { Product } \\
\text { Promotion }\end{array}$ & & X & & & $\mathrm{X}$ & $\mathrm{X}$ \\
\hline $\begin{array}{l}\text { Contacts for }+ \\
\text { info. }\end{array}$ & $\mathrm{X}$ & $\mathrm{X}$ & $\mathrm{X}$ & & $\mathrm{X}$ & $\mathrm{X}$ \\
\hline $\begin{array}{l}\text { Content sharing } \\
\text { (email / social } \\
\text { media) }\end{array}$ & & $\mathrm{X}$ & & $\mathrm{X}$ & & \\
\hline $\begin{array}{l}\text { Contact } \\
\text { directly by } \\
\text { email }\end{array}$ & & $\mathrm{X}$ & & $\mathrm{X}$ & $\mathrm{X}$ & $\mathrm{X}$ \\
\hline $\begin{array}{l}\text { Responsive } \\
\text { website }\end{array}$ & $\mathrm{X}$ & $\mathrm{X}$ & $\mathrm{X}$ & $\mathrm{X}$ & $\mathrm{X}$ & $\mathrm{X}$ \\
\hline
\end{tabular}

Such 'emotional' communication strategy alignment with brand values was also adopted by Volvo, although not emphasized to the same degree as BMW. Volvo's used-vehicle website was mainly designed around car search and selection tools, and it was careful to present the information in an appealing way through presenting eye-catching images and titles, wherein some of the brand's concepts and values were conveyed. Another interesting feature of Volvo's website was the use of thumbnails of car models in the configurator tool on the main page. This detail helps the user to perform an easier and more informed search. The least positive point of this website was the detailed presentation of each selected car, which revealed certain inconsistencies with the information organization and hierarchy.
Hallmark of Mercedes-Benz's used car website, on the other hand, was the simplicity of the search process, however, weaknesses pertaining to the content were apparent, particularly in terms of the lack of information about the advantages of acquiring a used car at the brand's official dealers. In addition, there was a lack of information about the brand's mission and vision, as well as images and graphics that could connect users emotionally to the brand's values and principles.

Of all the examples analysed, Audi's website was clearly the least interesting. The search tools were not optimally functional, and represented an obstacle in accessing information. In both the mobile and desktop versions of the website, several poorly distributed and organized information text blocks made it difficult to read the content. The website interface was also noticingly unattractive, replete with monochrome tones and outdated graphics. The photography of the vehicles though was of high quality which somewhat accentuated their perceived value.

Furthermore, the websites of Stand Virtual and CarNext were analyzed. These represent the largest and most popular online portals in Portugal for buying and selling used cars from most major brands. They were primarily directed at private entities and individuals.

Although the communication strategy of Stand Virtual and CarNext was different from what is intended by the Lexus group, they were considered important references since they dominate the used car sales market. Unlike Lexus, the target audience of the two companies is eclectic, seeking a diverse variety of cars from different brands.

Overall, both websites had a well-structured homepage with good content hierarchy. They did not have spaces dedicated to lifestyle concepts, wellness, or promotional texts. Both websites focused on two objectives: product search through filters, strategically positioned at the beginning of the page and easy to navigate; and inviting the user to make their product available for sale on the respective online platform. There was also a 'testimonials' section in CarNext's platform, which augmented the credibility of the service. This feature was considered a good reference and was correspondingly adopted in the development of the new Lexus platform.

In summary, it was found that, with the exception of BMW, the websites of the competitors were mainly limited to working as online platforms for searching and promoting vehicles available for sale.

BMW's website was the one that proved to be the closest to the intended solution for Lexus Portugal, providing relevant information about the brand and its services; and exploring images and videos with a more emotional outlook. However, the website's graphic and image component was not as refined as the brand's main website (bmw.pt), for the Portuguese market.

In accordance, the proposed prototype for Lexus Portugal intends to create a greater degree of integration between the main website of Lexus Portugal and its pre-owned division, presenting coherent solutions with the same level of graphic and image quality. 
Following this competitor review, the corresponding developed work focused on the design and development of the Lexus used car online platform that was presented.

\section{Online platform development}

The design process of the online platform was developed along the following phases, in conjunction with regular feedbacks from the Lexus Portugal and Caetsu teams:

\subsection{Interviews and definition of the Personas}

The concept of personas was created to define the target audience of the digital solution under study. Personas are fictional personalities that can characterize potential users, representing the aspirations and attributes of a target group that a brand entity seeks to communicate with. Such idealization process can help understand the needs, experiences, behaviors, and ambitions associable with the target users. Personas are meant to simplify the design process, from the point of view that all processes are developed from the perspective of the user in order to ensure the best user experience for the target audience [19-21].

In order to define the personas and to generate a better understanding of the overall context of Lexus's used car market segment, including the aims and aspirations of the brand and its customer segment, a set of interviews was conducted with Lexus Portugal executives (CEO, Sales Manager, Brand and Product Director, and Digital Marketing Manager) and the creative lead from Caetsu responsible for Lexus' communication and advertising. The interviews were of a structured type, previously scripted, and consisted of open questions.

Through these interviews it was found that the Lexus client is mainly male, over 50 years old, and is positioned in the upper to upper-middle class social bracket. However, the brand's goal is to extend its target audience to younger age groups, from the age of 30 onwards, and particularly to the female public. It was also found that Portuguese customers are still unclear about the main advantages of hybrid technology. Moreover, when the customer visits a dealer of the brand, the vast majority have no knowledge about the available after-sales services or customization options for used cars.

These results reinforce our conviction about the need to develop an online platform that is not simply a search tool for used cars available for sale. Decision making when buying a car is increasingly influenced by previous online searches, before even visiting the physical sales stands [22]. For this reason, it is essential to make the complete information set available online: not only about the products, but also about the brand, the offered services, the sales conditions, and technological specifications, among other related data.

The personas were developed with the support of the Lexus Portugal's and Caetsu's teams. In defining the personas (as shown in Table 2), the research thus took into account not only the type of usual customer, but also the youth and female target segments that Lexus also wants to reach out to.

Three types of personas were defined, two female and one male. The majority are female, contrary to the results on the type of visitors that Lexus Portugal has had on its website (www.lexus.pt). In 2020, the majority of visitors to Lexus Portugal's website (approximately 65\%) were male, with an average age of close to 45 years.

Table 2: Analysis grid of different personas.

\begin{tabular}{|c|c|c|}
\hline $\begin{array}{l}\text { JÕ̃O } \\
45 \text { years old }\end{array}$ & $\begin{array}{l}\text { LEONOR } \\
28 \text { years old }\end{array}$ & $\begin{array}{l}\text { SOFIA } \\
55 \text { years old }\end{array}$ \\
\hline $\begin{array}{l}\text { Architect in a studio in } \\
\text { Lisbon and a } \\
\text { technology lover. }\end{array}$ & $\begin{array}{l}\text { Team coordinator, in } \\
\text { an information } \\
\text { technology company. }\end{array}$ & $\begin{array}{l}\text { Medical specialist at a } \\
\text { Coimbra Hospital }\end{array}$ \\
\hline $\begin{array}{l}\text { Features: } \\
\text { João feels the need to } \\
\text { buy a car that promotes } \\
\text { safe, pleasant driving } \\
\text { and, if possible, with a } \\
\text { low environmental } \\
\text { impact. He is looking } \\
\text { for an excellent driving } \\
\text { experience, but above } \\
\text { all he wants a good } \\
\text { deal. During his } \\
\text { research, João realized } \\
\text { that there are several } \\
\text { technological solutions } \\
\text { that cover sustainability } \\
\text { concerns, and } \\
\text { economic and } \\
\text { technological } \\
\text { consumption, without } \\
\text { giving up comfort and } \\
\text { luxury. } \\
\text { Despite finding various } \\
\text { platforms for car sales, } \\
\text { and looking for the best } \\
\text { price, he prefers to } \\
\text { invest in a safe } \\
\text { purchase. } \\
\text { Besides all issues } \\
\text { related to the product, } \\
\text { João has doubts } \\
\text { regarding the choice of } \\
\text { the car brand and, for } \\
\text { that, he tries to research } \\
\text { the benefits and } \\
\text { conditions offered by } \\
\text { the various brands in } \\
\text { their proprietary } \\
\text { websites. }\end{array}$ & $\begin{array}{l}\text { Features: } \\
\text { Leonor lives far from } \\
\text { her job and her old car } \\
\text { is beginning to show } \\
\text { the need for } \\
\text { replacement with a } \\
\text { more modern option } \\
\text { that is safe and } \\
\text { comfortable. As her } \\
\text { everyday commutation } \\
\text { is long, she is looking } \\
\text { for an economical and } \\
\text { durable solution. These } \\
\text { constraints encourage } \\
\text { Leonor to search for } \\
\text { brands that have low } \\
\text { maintenance cost, } \\
\text { extended warranty } \\
\text { services, and which } \\
\text { offer excellent after- } \\
\text { sales customer service. } \\
\text { Beyond these concerns, } \\
\text { Leonor is also aware } \\
\text { that this is an important } \\
\text { purchase and should be } \\
\text { very well considered, } \\
\text { which leads her to } \\
\text { research, systematically } \\
\text { and carefully, in trying } \\
\text { to rationalize the } \\
\text { choices as much as } \\
\text { possible. }\end{array}$ & $\begin{array}{l}\text { Features: } \\
\text { Sofia usually leaves } \\
\text { work late, and at the } \\
\text { end of the day, enjoys } \\
\text { her ride home relaxing } \\
\text { in a car that offers } \\
\text { unmatched comfort and } \\
\text { luxury. She is looking } \\
\text { to upgrade from her } \\
\text { present one and } \\
\text { promptly searches on } \\
\text { her phone for the best } \\
\text { deals available. She } \\
\text { immediately quits from } \\
\text { websites that feel } \\
\text { clunky or too } \\
\text { complicated, and gives } \\
\text { clear preference to } \\
\text { websites that are easy } \\
\text { to navigate on her } \\
\text { phone, and which } \\
\text { provide the most } \\
\text { relevant information } \\
\text { upfront. Sofia considers } \\
\text { it fundamental that the } \\
\text { contents made } \\
\text { available on the } \\
\text { website are presented } \\
\text { in a language and style } \\
\text { that is simple, direct } \\
\text { and easy to understand, } \\
\text { and which does not get } \\
\text { too technically } \\
\text { complex. She knows } \\
\text { the Lexus brand well as } \\
\text { it is a frequent choice } \\
\text { of her family members. }\end{array}$ \\
\hline
\end{tabular}

This type of majority audience is represented in the persona identified with the name João. This persona is also close to the type of Lexus customer, which is characterized by its focus on economy, the environment, security, reliability and technology.

However, the brand aims to change this trend and ensure that the younger and female audiences who visit the website do so successfully. The personas Leonor and Sofia intend to represent these customers' segments.

The persona Leonor represents the younger age group, which generally has less purchasing power. For this reason, buying a semi-new or used car can be a good option. They are people who buy cars for a long period of time and therefore prefer to make a slightly higher investment in the purchase in order to guarantee that it is a safe and reliable investment. Therefore, they prefer cars with high reliability, low maintenance costs and safety.

The persona Sofia represents the oldest age group, which usually has little availability and patience to seek information, especially in digital media. For this reason, it is fundamental to 
have an online platform with good usability and that presents in a direct and brief way the main attributes of the brand's products and services. Although the typical client of the brand is male and above 50 years, the female gender is also important. According to internal Lexus Portugal studies, the female gender usually has a high influence on the purchasing decision of a relative, namely the partner (boyfriend or husband).

\subsection{Information architecture}

According to Garrett [23], the success of the user experience depends upon the designer's consideration of the following set of assumptions in the construction of information architecture [24, 25]:

- Strategy: represents what the user expects from the digital product.

- Objectives: requirements and specifications of functionalities that the product should meet.

- Structure: definition of hierarchies and content organization.

- Survey of technical limitations and usability of the product.

- Skeleton: design of the organization of the elements that will constitute the interface.

- Surface: corresponds to the final phase of the digital product, what the user interacts with.

In accordance with the needs as outlined by the Caetsu and Lexus team, a set of features and sections were defined for the digital product. The navigation experience was first established for the online platform to be well structured. During this initial stage, difficulties and possible obstacles regarding the user's experience was also anticipated [26].

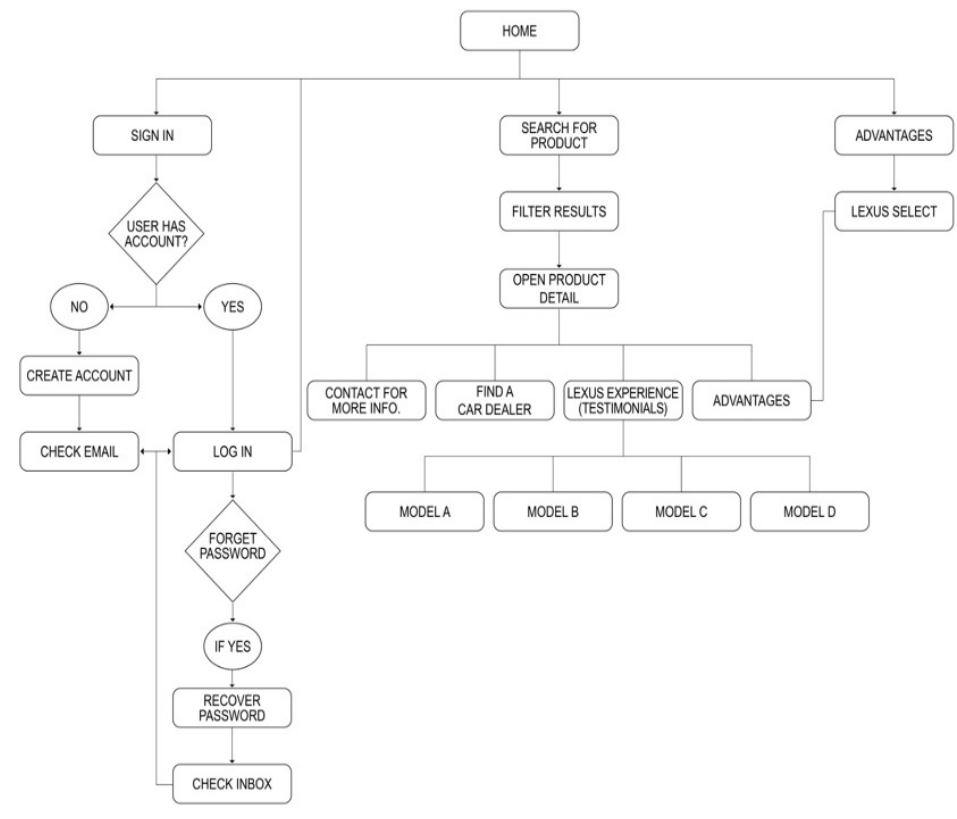

Figure 1: User flow diagram

\subsection{Wireframes and user flows}

After characterizing the personas and defining their main needs, the first low fidelity sketches, or wireframes, were created. These sketches were made by means of basic representation through shapes, with the objective of studying the disposition of contents and the functionality of each page. The sketches were at www.astesj.com first drawn manually and then transferred digitally, allowing the skeleton of the online platform to be visualized.

Further on, in order to study the sequence of steps for the user to accomplish a certain task, user flows (as shown in Figure 1) were developed towards establishing performance parameters for each task. User flows are considered fundamental for the organization of wireframes in order to understand step by step the user's navigation intentions. For the development of the user flows the Sketch software was used, allowing to test the interaction between the different wireframes through simple graphic representations.

After this first phase, the first screens were designed, and later on, a set of detailed drawings, typography, icons, buttons, and other interactive elements were added, which completed the navigation paths and the linking between pages and sections.

\subsection{Interface design}

It was deemed fundamental for the interface to incorporate a visually pleasant layout, which could help users to read, concentrate, and perform tasks without hinderances. The interface was also finetuned to generate predictable user behavior and provide the user a sense of control when using the product.

When an interface has a nice layout, it helps users to read, concentrate, perform tasks better and increase real and perceived usability $[27,28]$. The interface should generate predictable user behavior and give the user a sense of control when using the product.

\subsubsection{Grid}

Grids are practical tools in the structuring process and are responsible for the consistency and visual organization of the design and the elements that build the interface, and were thus considered essential in the design of the website [29].

Later on, a number of concepts linked with Responsive Web Design were used in order to create an interface that would be capable of adapting to various mobile devices, in accordance with the individual/situational preference of each user [30]. This was also done to create a cohesive, harmonious and balanced visual composition, towards ensuring optimal adaptability and to follow a structured logic throughout the procedure.

Due to the multiplicity of screen sizes, it was decided to define, in the desktop version, the current most used resolution in Portugal: 1366 pixels wide [31].

The grid used to build the desktop version of the platform was divided into twelve columns, each sixty pixels wide, with twenty pixels column gaps. At the end of each page, a margin corresponding to ten pixels was also incorporated.

In order to ensure a responsive layout that would adapt seamlessly to the interface format, similar parameters were considered: a screen width of 360 pixels (most prevalent locally), and a grid divided into twelve columns, each twenty-seven pixels wide and with a column gap of four pixels.

\subsubsection{Color Palette}

The design process in urderlined by the notion that the selection of the chromatic palette, during the UI Design process, 
does not depend squarely on aesthetic sense, but on the intention behind the application of each element. This could be so in terms of capturing viewer attention to certain points, transmitting certain sensations; improving navigation; or creating a sense of harmony between all the elements that make up the interface [32].

Color, however, is a fundamental part of communicating Lexus' history. The selected color set (as shown in Figure 2) mainly emphasized on bringing softer tones in order to convey the brand's luxury positioning and subtle refinement. A predominance of neutral colors was also meant to highlight the contextual photographs of environment and lifestyle in conjunction with products of the brand. More luminous colors were additionally used in some details to highlight the aspect of technological contemporaneity in the brand, and capture the user's attention to certain informative or interactive elements.

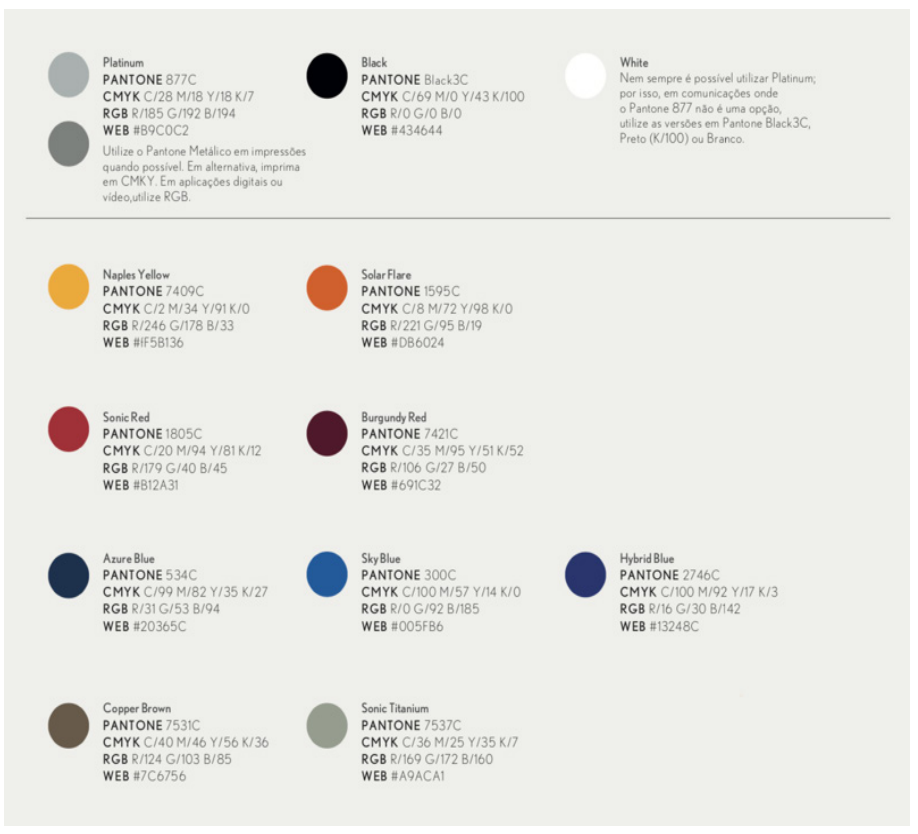

Figure 2: Brand Lexus Colour Palette

\subsubsection{Typography}

Bahat [33] views the use of the right typography as fundamental to guaranteeing readability, accessibility, hierarchy, and graphic balance. In digital products typography strongly influences the overall usability of the interface.

It is also one of the defining elements of a brand's visual identity. In the platform, the typographic family adopted was "Nobel" by Adobe Fonts, designed by Tobias Frere-Jones. It is a Sans Serif font, with several typographic styles and is suited to work correctly on digital media.

\subsection{Design of the online platform screens for the mobile and desktop versions}

According to Marketest [34], in the last 10 years, the use of the Internet through mobile devices has registered substantial growth in Portugal, especially through smartphones. As can be seen in Graph 1, in 2018 Internet use through smartphones surpassed desktop access. This trend has been determined to continue [34].

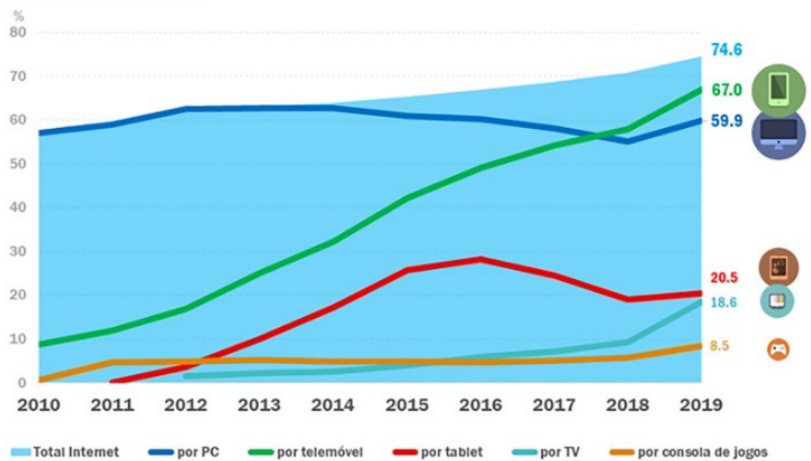

Graph 1: Internet use by platforms. Source: Marktest (2019)

For this reason, the design of the different screens of the platform focused on a mobile first approach and was then adapted to the desktop version. The strategic decisions that guided the design process behind the different screens were as follows:

- Homepage: Since it would be the first page that the user would have access to when visiting the website, the information and tools considered most relevant for the Lexus' target audience were highlighted, such as information on the advantages of the Lexus Select Service; information about the Lexus' experience (including access to testimonials from Lexus customers); and the possibility of searching immediately for available semi-new cars. As can be seen in figure 3 , on the homepage there is a predominance of photographs and graphics that are positioned to accentuate the environment and the identity of the Lexus brand. In this way, the above mentioned objective of designing an online platform that reflected the Lexus philosophy and a userfriendly experience, was addressed.
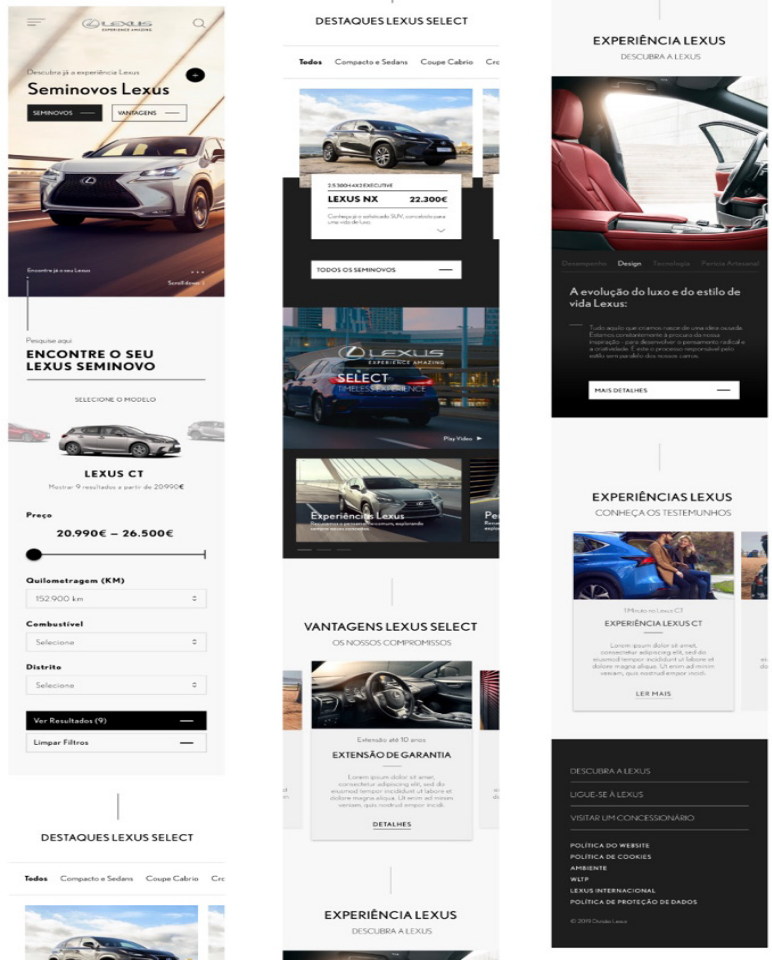

Figure 3: Lexus Homepage (mobile version) 
- Configurator: Represented by the search and filter section of the homepage, the configurator was incorporated in a subtle manner, and not emphasized, with a view to provide the user greater freedom of choice in navigation. In the configurator the images of the car models were highlighted, allowing an easier, faster and more informed search.

- Testimonials: The "Testimonials" section was created with the aim of reaching out through personal narratives, towards building trust and empathy between the user and the brand. In this section testimonials from Lexus vehicle owners were presented, alongside promotional videos and informative texts about the cars.

- "Start" buttons: In the introduction to the "Lexus Advantages" page, ignition-style start buttons (similar to those found physically on Lexus cars and used to actually start the car's engine) were strategically applied. Through this type of elements, the intention was to involve the user with the visual ethos of the brand and its cars.

- Dark Mode: The introduction of a view mode with a predominance of dark tones was applied on pages such as "Lexus Select Advantages" and "Testimonials", towards ensuring eye comfort, and for garnering greater concentration in reading on higher text density sections.

- Quiz: on the online platform a Quiz component was created (as shown in Figure 4), entitled "Discover the ideal Lexus for you", with the aim of bringing communication between the user and the brand closer. In this section, the users have an option to answer a small questionnaire in order to identify and share their main preferences. Upon obtaining the users' inputs, the website employs a set of algorithms to suggest the most suitable car model. The analysis of the inputs also provides real-time availability of suggested options, and the respective store locations with available stock. The results that do not directly match the user's needs, are displayed towards the end of the search page. This strategy was intended to contribute to increasing empathy between the users and the brand.
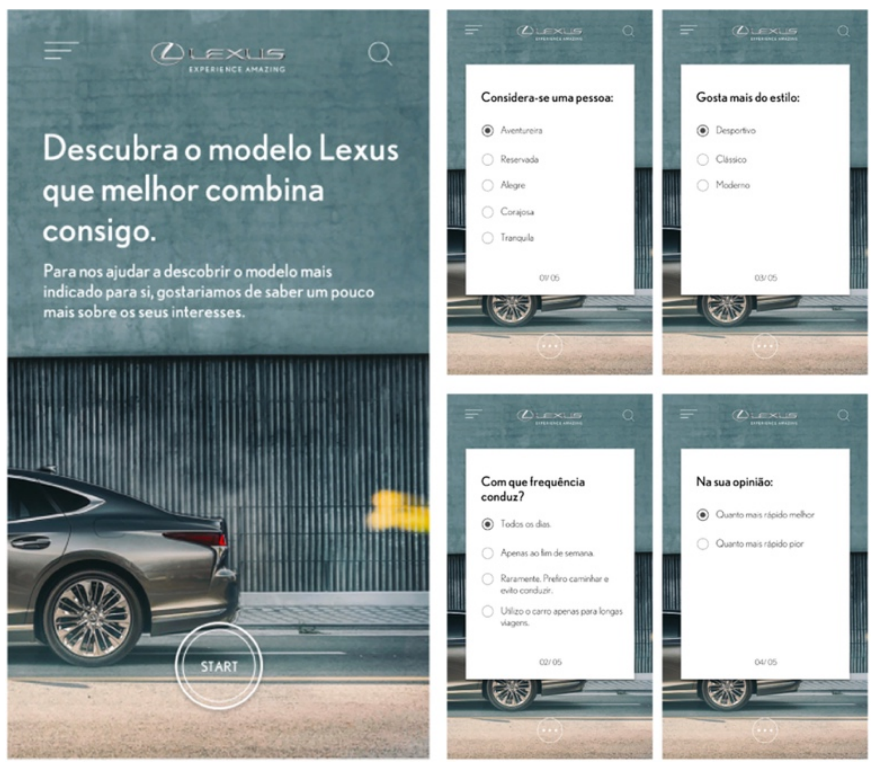

Figure 4: Quiz section (mobile version)
- Product listing: In this area the main characteristics of each car is presented, providing relevant information to viewers with illustrated icons that allow for an easier and faster reading experience. Also incorporated in the section are images of the respective cars, that are aligned to a predefined presentation standard, in order to ensure consistency and good image quality. Additionally, information pertaining to test-drive locations nearby is included.

As mentioned earlier, the mobile version of the platform was designed first, and then ported to the desktop version (as shown in Figure 5).
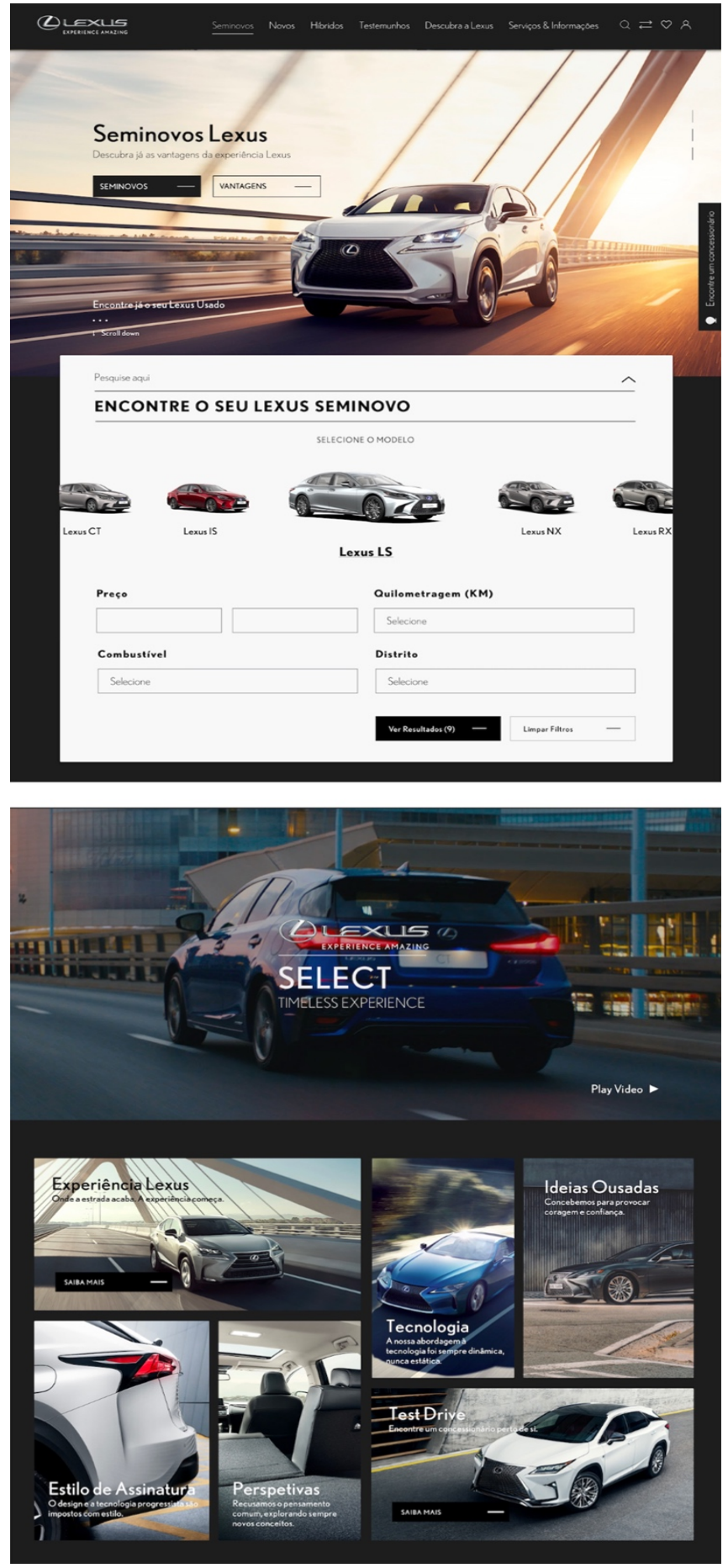

Figure 5: Homepage details (desktop version) 


\subsection{Prototype}

Upon concluding the designing of each screen of the mobile and desktop versions in the 'Sketch' application, the software 'Invision' was used to prototype the online platform. Through this software, animations and transitions between screens were produced and applied. This allowed a better understanding of the flow and navigation of the website, before moving on to the usability testing phase of the prototype.

\subsection{Usability tests}

The usability tests were composed of a series of actions that were aimed to evaluate and verify the user's ease of use of the interface. The tests were conducted with users representing each persona for whom the product was being developed. The participants carried out a list of tasks and objectives, while being analyzed to provide observations on behavioral data [35].

There are several methods to study and evaluate usability. According to Nielsen [16], through 5 users, $85 \%$ of the usability problems of the product or service can be detected.

Throughout the development of the online platform several usability tests were performed in order to obtain a constant feedback from users and make the necessary improvements accordingly. This process helped reach the last phase of the work with a reduced number of errors and inconsistencies in the interface design.

For the last usability tests, towards attaining further rigor in the analysis method, six individuals (two for each of the three defined personas), men and women aged between 27 and 58, were selected for the sample.

The tests consisted of observing and evaluating user behavior in performing the following tasks:

- Enter the website and find the car configurator.

- Select a car and find the respective data sheet.

- Take the test to find out which car is right for you and ask for more information about it.

- Create a user account on the website.

- Find out more about Lexus Select and its benefits.

- Go to the testimonials page of former Lexus vehicle owners.

Users were also asked to indicate the difficulties, indecisions and doubts they encountered.

The tests lasted an average of 12 minutes per individual. According to the observations made, the following findings stood out:

- All users were able to accomplish the proposed tasks without demonstrating difficulty in finding the intended goal. However, in task 3 , there was some indecision on the part of two of the users to start their task (by clicking on the button "The Lexus for you"). Taking this result into account, it was considered necessary to further highlight this functionality on the website, and subsequently improve it.
- The icons designed for the presentation of the car's technical data were highlighted by five users. These users considered this option an important aid in reading the contents.

- Older users took more time than newer users in performing the tasks. However, the difference was small.

After the usability tests, the same users were also asked to answer a short questionnaire towards assessing the level of satisfaction they experienced while using the online platform. The questionnaire was set to examine key areas such as the interaction, the perception of the information, the usefulness factor, and an overall impression of the website. In Table 3 the questions that have been asked to users are presented.

Table 3: The questions asked to users to evaluate the level of satisfaction experienced while using the online platform.

\begin{tabular}{|c|} 
QUESTIONS \\
\hline Perception and quality of the information \\
\hline All the information on the website was readable? \\
\hline Did you understand all the content of the website? \\
\hline Is the information on the website well organized by the different parts of \\
the website? \\
\hline If youness \\
\hline Has the website enabled you to become more enlightened about the brand's \\
products? \\
\hline Did the website clearly conveyed the advantages of buying a Lexus used \\
car? \\
\hline Interaction
\end{tabular}

The results of these tests were reasonably positive. The tests demonstrated a high success rate in the overall fulfillment of tasks, identifying only minor problems that were correspondingly solved. The level of user satisfaction, based on the feedback obtained through the questionnaire, was high and thus determinative of the prototype's market-readiness.

\section{Conclusions}

As for the first of the specific objectives, the joint work with Lexus and the Caetsu agency allowed, in the first instance, to identify that the brand's strategy, beyond a better conversion ratio of the digital platform, was interested in promoting values related 
to the circular economy, sustainability and responsible use of natural resources, which was a fully consistent action with offering a new life to used cars, even more so when these vehicles are almost entirely hybrid vehicles. Secondly, it allowed, in line with its strategy, to identify and model typical users based on the research data that the brand already had.

Secondly, the study concluded that, with the exception of BMW, the websites of the competing brands were mainly limited to serving as search tools for their respective used cars available for sale. The analysis of the competing brands, together with the collaborative research actions developed with the Lexus Portugal and Caetsu teams, provided a comprehensive understanding of the second-hand car segment in Portugal, and gave an idea of Lexus' target audience.

Regarding the third secondary objective, the methodological foundations of the design and development process of the online platform facilitated the realization of a viable solution by strictly adhering to the key principles of UX and UI design to achieve cohesion between the different elements of the process, such as the application of character models, information architecture, the creation of frameworks and user flows and the conceptualization of appropriate interfaces.

In addition, usability tests were conducted to evaluate user acceptance and identify areas for improvement. Once the necessary changes had been made, the prototype was submitted to the management of Lexus Portugal, which subsequently approved it and granted permission to move on to the execution phase, with a view to making it public in the coming months.

Thus, the results presented allow to claim that the online platform designed in this research can align the strategic interests of Lexus with those of its users, allowing Lexus Portugal to have a distinctive and even more complete solution compared to competing brands and entities, and to provide users with a solution more suited to their needs, goals and motivations.

Although user studies indicate a good result in terms of usability and user experience, in the future it's necessary to carry out further testing of the implemented product, in order to iteratively add improvements to it.

Based on the results, it is understood that the process employed in this research can be used in those cases where the strategic interests of the brands are to be aligned with those of the previously identified target audiences.

The process used in this research is intended to be the basis of a model that helps brands to align their strategic interests with the needs, expectations and objectives of their potential users. All of this is done from a design perspective and with the aim of turning their audience (potential customers) into satisfied users.

\section{Conflict of Interest}

The authors declare no conflict of interest.

\section{Acknowledgements}

This work is financed by national funds through the FCT Fundação para a Ciência e a Tecnologia, I.P., under the scope of the project UIDB/04057/2020.

\section{References}

[1] G. Pedros-Perez, P. Martínez-Jiménez, P. Aparicio-Martinez, "The potential of car advertising in pursuing transport policy goals: Code of good practices in the Spanish context" Transportation Research Part D: Transport and Environment, 72, 312-332, 2019. https://doi.org/10.1016/j.trd.2019.05.010

[2] A. Boelhouwer, A.P. van den Beukel, M.C. van der Voort, C. Hottentot, R.Q. de Wit, M.H. Martens, "How are car buyers and car sellers currently informed about ADAS? An investigation among drivers and car sellers in the Netherlands" Transportation Research Interdisciplinary Perspectives, 4, 2020 https://doi.org/10.1016/j.trip.2020.100103

[3] Paulo Dinis, Fernando Moreira da Silva, "The Passenger Car in Portugal: Features of Functional Modules" Procedia Manufacturing, 3, 312-332, 2015. https://doi.org/10.1016/j.promfg.2015.07.313

[4] Z. Kahraman, "Using user-centered design approach in course design" Procedia - Social and Behavioral Sciences, 2(2), 2071-2076, 2010. https://doi.org/10.1016/j.sbspro.2010.03.283

[5] J. Braga, "Is human-centered Design broken?". UX Collective, 2019. [Online]. Available: https://uxdesign.cc/is-human-centred-design-brokencac130eecc48. [Accessed: 28-Aug-2019]

[6] A. Chammas, M. Quaresma, C. Mont'Alvão, "A Closer Look on the User Centred Design" Procedia Manufacturing, 3, 5397-5404, 2015. https://doi.org/10.1016/j.promfg.2015.07.656

[7] J. Liedtka, "Why Design Thinking Works". Harvard Business Review, 2018. [Online]. Available: https://hbr.org/2018/09/why-design-thinking-works.

[8] C. F. Llema, C. M. Vilela-Malabanan, "Design and Development of MLERWS: A User-Centered Mobile Application for English Reading and Writing Skills" Procedia Computer Science, 161, 1002-1010, 2019. https://doi.org/10.1016/j.procs.2019.11.210.

[9] C. Abras, D. Maloney-Krichmar, J. Preece, User-Centered Design. In Bainbridge, W. Encyclopedia of Human-Computer Interaction. Thousand Oaks: Sage Publications, 2004.

[10] D. A. Noman, The Design of everyday things, New York: Basic Books, 2013.

[11] N. Martins, D. Brandão, D. Raposo (Eds.), Perspectives on Design and Digital Communication: Research, Innovations and Best Practices, Cham: Springer, 2021. https://doi.org/10.1007/978-3-030-49647-0.

[12] D. Raposo, "From Brand Mark to Corporate Visual Identity Systems" Convergências Journal, 2(3), 2009. Retrieved from journal URL: http://convergencias.esart.ipcb.pt/?p=article\&id $=40$

[13] J. Park, "Developing a knowledge management system for storing and using the design knowledge acquired in the process of a user-centered design of the next generation information appliances" Design Studies, 32(5), 482-513, 2011. https://doi.org/10.1016/j.destud.2011.05.001

[14] D. Brown, "Chapter 2 - Agile Methods + UX = Agile UX" In Diana DeMarco Brown (Eds.), Agile User Experience Design: A Practitioner's Guide to Making It Work. 39-69, 2013. https://doi.org/10.1016/B978-0-12-4159532.00002-9

[15] M. Kouprie, F. Sleeswijk Visser, "A framework for empathy in design: stepping into and out of the user's life" Journal of Engineering Design, 20(5), 437-448, 2009. https://doi.org/10.1080/09544820902875033

[16] J. Nielsen, "Enhancing the explanatory power of usability heuristics" in Proceedings of the SIGCHI Conference on Human Factors in Computing Systems (CHI '94). Association for Computing Machinery, New York, NY, USA, 152-158, 1994. https://doi.org/10.1145/191666.191729

[17] N. Martins, M. Lemos, D. Brandão, D. Raposo, J. Neves, J. Silva, "Lexus used-vehicle online platform: comparative analysis of major competing brands' websites" in Advances in Design, Music and Arts: Proceedings of the 7th Meeting of Research in Music, Arts and Design, EIMAD 2020, May 14 15, 2020. Springer Series in Design and Innovation, 9. Springer, Cham, 243255, 2021. https://doi.org/10.1007/978-3-030-55700-3 17.

[18] D. Lachapelle, "A Designer's Guide to Competitor Research". Wayfair Experience Design, 2017. [Online]. Available: https://medium.com/wayfairdesign/a-designers-guide-to-competitor-research-914b0deee25a. [Accessed: 23-Jul-2019]

[19] R. Dam \& T. Siang, "Personas: A Simple Introduction". Interaction Design Foundation. [Online]. Available: https://www.interactiondesign.org/literature/article/personas-why-and-how-you-should-use-them.

[20] A. Cooper, R. Reimann, D. Cronin, About Face 3: The essentials of interaction design. Information Visualization, 3, Canada: Wiley Publishing, Inc, 2007.

[21] F. Anvari, D. Richards, M. Hitchens, M. Ali Babar, H. Tran, P. Busch, "An empirical investigation of the influence of persona with personality traits on conceptual design" Journal of Systems and Software, 134, 324-339, 2017. https://doi.org/10.1016/j.jss.2017.09.020

[22] A. Teixeira, "Como está a evoluir o E-Commerce em Portugal em 2020". Digitalks, 2020. [Online]. Available: https://digitalks.pt/artigos/a-evolucaodo-e-commerce-em-portugal.

[23] J. J. Garret, The elements of the user experience. Berkeley: New Riders, 2003. 
[24] R. Hartson, P. Pyla, "Chapter 16 - Designing the Ecology and Pervasive Information Architecture" In Rex Hartson \& Pardha Pyla (Eds.), The UX Book (Second Edition). 341-358, 2019. https://doi.org/10.1016/B978-0-12805342-3.00016-3

[25] A. Grilo, "O que é Arquitetura da Informação e como ela influencia a UX do seu produto". Comunidade UX Design Natal, 2016. [Online]. Available: https://medium.com/ux-design-natal/o-que-\%C3\%A9-arquitetura-dainforma $\% \mathrm{C} 3 \% \mathrm{~A} 7 \% \mathrm{C} 3 \% \mathrm{~A} 30$-e-como-ela-influencia-a-ux-do-seu-produtob4f20881b2b4.

[26] F. Santana, "Arquitetura de Informação e o seu propósito". Coletivo UX, 2017. [Online]. Available: https://coletivoux.com/arquitetura-de-informaçãoe-o-seu-propósito-29cd278ebdfe.

[27] K. Kashimura, M. Kurosu, "Apparent usability vs. inherent usability: experimental analysis on the determinants of the apparent usability" in CHI '95: Conference Companion on Human Factors in Computing Systems. 292293, 1995. https://doi.org/10.1145/223355.223680

[28] N. Tractinsky, A.S. Katz, D. Ikar, "What is beautiful is usable" Interacting with Computers, 13(2), 127-145, 2000. https://doi.org/10.1016/S09535438(00)00031-X

[29] M. Soegaard, "The Grid System: Building a Solid Design Layout". Interaction Design Foundation, 2019. [Online]. Available: https://www.interactiondesign.org/literature/article/the-grid-system-building-a-solid-design-layout.

[30] E. Marcotte, Responsive web design, Paris: Eyrolles, 2011

[31] StatCounter GlobalStats, "Screen Resolution Stats Portugal (Nov 2018 - Nov 2019)". StatCounter, 2019. [Online]. Available: https://gs.statcounter.com/screen-resolution-stats/all/portugal.

[32] T. Schlatter, D. Levinson, "Chapter 6 - Color" In Tania Schlatter, Deborah Levinson (Eds.), Visual Usability: Principles and Practices for Designing Digital Applications. 171-211, 2013. https://doi.org/10.1016/B978-0-12398536-1.00006-1

[33] N. Bahat, "Improving UI Design Through Better Typography". Awwwards, 2015. [Online]. Available: https://www.awwwards.com/improving-uidesign-through-better-typography.html.

[34] Marktest, "Acesso à internet em Portugal é cada vez mais Mobile". Grupo Marktest, $2019.2 \quad$ [Online]. https://www.marktest.com/wap/a/n/id 2555.aspx.

[35] J. Nielsen, "Disruptive Workflow Design”. Nielsen Norman Group, 2012. [Online]. Available: https://www.nngroup.com/articles/disruptive-workflowdesign. 